\title{
La administración de ondansetrón no mejora la evolución de los niños con gastroenteritis aguda sin deshidratación
}

\author{
Administration of ondansetron does not improve the course of children with acute gastroenteritis without dehydration
}

Mauricio P Kemnitz ${ }^{\mathrm{a}}$ (i)

\begin{abstract}
Resumen
Sobre la base de una viñeta clínica de un niño con gastroenteritis aguda sin deshidratación, el autor de este artículo realiza una búsqueda bibliográfica para revisar la evidencia que avala el uso de ondansetrón para tratar sus vómitos, práctica bastante común en instituciones con acceso a este fármaco en sus centrales de emergencia.

Luego de dicha búsqueda, el autor concluye que en niños con gastroenteritis aguda sin deshidratación, la administración de ondansetrón no reduce la necesidad de hidratación intravenosa ni la frecuencia ni la severidad de los vómitos.

Abstract

Based on a clinical vignette of a child with acute gastroenteritis without dehydration, the author of this article performs a literature search to review the evidence supporting the use of ondansetron to treat his vomiting, a fairly common practice in institutions with access to this drug in their emergency rooms. After this search, the author concludes that in children with acute gastroenteritis without dehydration, the administration of ondansetron does not reduce the need for intravenous hydration or the frequency or severity of vomiting.
\end{abstract}

Palabras clave: Gastroenteritis, Ondansetrón, Niño, Preescolar. Keywords: Gastroenteritis, Ondansetron, Preschool, Child.

Kemmitz MP. La administración de ondansetrón no mejora la evolución de los niños con gastroenteritis aguda sin deshidratación. Evid Actual Pract Ambul. 2020;23(4):e002076.

\section{Escenario clínico}

Se presenta a la central de emergencias pediátricas un niño de 4 años de edad acompañado por su familiar a cargo quien refiere cuadro agudo de vómitos asociado a deposiciones desligadas de un día de evolución. El médico a cargo de la consulta, realiza una anamnesis detallada sobre antecedentes personales, medicación habitual, características de las deposiciones, presencia de fiebre y/o síntomas acompañantes, asociado a un examen físico con el cual arriba al diagnóstico presuntivo de gastroenteritis aguda sin deshidratación, indicando de esta forma medidas higiénico dietéticas, pasos a seguir para una correcta hidratación, y pautas de alarma. Finalmente indica una dosis única de ondansetrón vía oral para evitar el riesgo de deshidratación asociado a vómitos.

\section{Pregunta que generó el caso}

En niños con vómitos secundario a gastroenteritis aguda sin deshidratación: el tratamiento con ondansetrón en dosis única, ¿disminuye el riesgo de deshidratación, en comparación con aquellos que no lo reciben?

\section{Estrategia de búsqueda}

Se realizó una búsqueda en PubMed utilizando como palabras clave: "gastroenteritis", "ondansetron" y "dehydration". Se obtuvieron 46 resultados a los cuales se les aplicó el filtro "publicados en los últimos cinco años", quedando un remanente de 15 artículos.

\section{Algunos datos sobre cuadros de gastroenteritis aguda en pacientes pediátricos}

La gastroenteritis aguda (GEA) es un síndrome clínico a menudo definido por el aumento de la frecuencia de deposiciones (p. ej. más de tres heces sueltas o acuosas en 24 horas o una cantidad de deposiciones sueltas/acuosas que excede el número habitual de deposiciones diarias del niño en dos o más), con o sin vómitos, fiebre o dolor abdominal. Suele durar menos de una semana y con predominancia de origen viral, siendo el rotavirus el agente causal más frecuente ${ }^{1}$.
El historial y el examen de niños con signos y síntomas de gastroenteritis se centran en determinar la gravedad de la enfermedad, haciendo foco en detectar la presencia o no de deshidratación y evaluando otras causas de diarrea y/o vómitos que requieran de una terapia definitiva o que puedan confundirse con GEA durante los primeros días de inicio ${ }^{1}$.

El diagnóstico de GEA se realiza por el historial característico de diarrea que no contiene sangre o moco macroscópico; asociada o no a vómitos, fiebre o dolor abdominal. La evaluación de laboratorio generalmente no es necesaria, pero puede justificarse en algunos casos ${ }^{1}$

La GEA viral suele ser una enfermedad aguda y autolimitada que no requiere terapia farmacológica. La terapia inicial se dirige a corregir el déficit de líquidos, con reposición de acuerdo al grado de deshidratación. No se recomienda el uso de agentes antidiarreicos ${ }^{1}$.

Si bien el uso de antieméticos no está recomendado en forma rutinaria para niños mayores de seis meses de edad con sospecha de gastroenteritis viral, en algunas situaciones clínicas que incluyen deshidratación leve a moderada y vómitos intensos y/o persistentes que interfieren con la terapia de rehidratación oral (TRO), dosis únicas vía oral de ondansetrón a $0,15 \mathrm{mg} / \mathrm{kg}$ de peso (dosis máxima de $8 \mathrm{mg}$ ) han demostrado ser beneficiosas ${ }^{2}$. Sin embargo en niños que no están deshidratados, estos beneficios no están probados ${ }^{3}$.

\section{Resumen de la evidencia}

Se seleccionó sólo un ensayo clínico aleatorizado ${ }^{3}$, el único estudio que incluyó población sin deshidratación y cumplía con los criterios para responder nuestra pregunta.

\section{Freedman SB, et al. Oral ondansetron administration to non dehydrated children with diarrhea and associated vomiting in emergency departments in Pakistan: a randomized controlled trial. Ann Emerg Med. 2019;73(3):255-65.}

Objetivo. Evaluar si la administración de una dosis única de ondansetrón por vía oral en niños con vómitos secundarios a GEA

\footnotetext{
a Servicio de Medicina Familiar y Comunitaria, Hospital Italiano de Buenos Aires. mauricio.kemnitz@hospitalitaliano.org.ar
} 
no deshidratados, reduce la necesidad de rehidratación endovenosa (indicador indirecto de deshidratación grave).

Diseño. Ensayo clínico aleatorizado, doble ciego, controlado con placebo, realizado en un departamento de emergencias en Karachi, Pakistán. Fueron reclutados niños de seis meses a cinco años de edad sin deshidratación, que estuvieran cursando una diarrea con al menos un episodio de vómitos durante las últimas cuatro horas desde su llegada al centro de atención. Fueron asignados aleatoriamente a una dosis única de ondansetrón por vía oral o a placebo.

Definición de los resultados principales. El resultado primario fue necesidad de rehidratación endovenosa (administración mayor o igual a $20 \mathrm{~mL} / \mathrm{kg}$ de un líquido isotónico durante 4 horas) durante las siguientes 72 horas posteriores a la aleatorización. Los resultados secundarios fueron la presencia y frecuencia de vómitos, la necesidad de hospitalización por más de 24 horas, el volumen de solución de rehidratación oral consumida, el número de deposiciones diarreicas y el fracaso del tratamiento, este último definido como la ocurrencia de alguno de las siguientes desenlaces: necesidad de rehidratación intravenosa, rehidratación nasogástrica durante más de 24 horas o muerte dentro de las primeras 72 horas.

Los resultados exploratorios incluyeron eventos adversos graves, necesidad de unidad de cuidados intermedios y admisión en unidad de cuidados intensivos, volumen de la diarrea durante las cuatro horas siguientes y estado de hidratación a las 72 horas.

Resultados. De un total de 2.229 candidatos, terminaron siendo aleatorizados 626. La mediana de edad de los participantes fue de 15 meses (intervalo intercuartilo, 10 a 26 ) y $59,4 \%$ eran varones. Los grupos estuvieron bien balanceados respecto de las principales características de interés. La Tabla 1 resume los resultados principales del estudio.

Tabla 1. Resultados en los desenlaces principales evaluados durante las primeras 72 horas. Fuente: Freedman SB, et al. Ann Emerg Med. 2019;73(3):255-65. Nota: IC: Intervalo de Confianza.

\begin{tabular}{|l|c|c|c|c|}
\hline Desenlaces & Ondansetron $\mathrm{n}=312$ & Placebo $\mathrm{n}=314$ & Odds Ratio (IC 95\%) & $\%$ Diferencia (IC $95 \%)$ \\
\hline $\begin{array}{l}\text { Recibió más de } 20 \mathrm{~mL} / \mathrm{kg} \text { de hidratación } \\
\text { intravenosa }\end{array}$ & $32 / 312(10,2 \%)$ & $34 / 314(10,8 \%)$ & $0,95(0,56$ a 1,59) & $-0,6 \%(-5,5$ a 4,3$)$ \\
\hline Necesitó rehidratación intravenosa & $37 / 312(11,9 \%)$ & $38 / 314(12,1 \%)$ & $0,98(0,60$ a 1,61) & $0,2 \%(-4,9$ a 5,4$)$ \\
\hline Vomitó & $61 / 312(19,6 \%)$ & $75 / 314(24 \%)$ & $0,77(0,53$ a 1,13) & $-4,3(-10,8$ a 2,1) \\
\hline
\end{tabular}

Los resultados de un análisis multivariable, que ajustó por el potencial efecto de haber recibido algún agente antiemético antes de la aleatorización, no modificó los resultados (Odds Ratio 1,41; Intervalo de Confianza del $95 \%$ : 0,71 a 2,77). Tampoco hubo diferencias estadísticamente significativas entre ambas ramas de tratamiento en el número de vómitos, en el volumen total de solución de rehidratación oral consumida, en el número de deposiciones diarreicas ni en la tasa de hospitalización.

Conclusión de los autores. La administración oral de una dosis única de ondansetrón no resultó en una reducción en el uso de rehidratación intravenosa ni modificó resultado clínico alguno.

\section{Conclusiones y recomendaciones}

Contábamos con evidencia de la utilidad de la administración de ondansetrón en niños con formas graves de GEA con vómitos -ya con deshidratación al momento de recibir este fármacoen términos de una disminución en la necesidad de rehidratación endovenosa en comparación con los niños que recibieron place- bo $^{2}$. Sin embargo, el ensayo clínico que acabamos de resumir documentó el uso de esta droga no mejora los resultados clínicos de niños con formas menos severas de GEA con vómitos (sn deshidratación $)^{3}$.

Estos hallazgos no sorprenden ya que durante la última década se vienen constatando aumentos significativos en el uso de de esta droga en EE.UU., sin que se hayan reducido las tasas de rehidratación intravenosa ${ }^{4}$.

Para concluir, destacamos que esta evidencia es concordante con las recomendaciones de la Sociedad Canadiense de Pediatría, que sugiere considerar el uso de una dosis única de ondansetrón oral solamente en niños de seis a 12 meses de edad con cuadros de vómitos por GEA y deshidratación leve a moderada o falla de la TRO ${ }^{5}$.

Recibido el 29/06/2020 Aceptado el 29/07/2020 y Publicado el 24/09/2020.

\section{Referencias}

1. Guarino A, Ashkenazi S, Gendrel D, et al. European Society for Pediatric Gastroenterology, Hepatology, and Nutrition/European Society for Pediatric Infectious Diseases Evidence-Based Guidelines for the Management of Acute Gastroenteritis in Children in Europe. J Pediatr Gastroenterol Nutr. 2014;59(1):132-152. Available from: 10.1097/mpg.0000000000000375;https://dx.doi.org/10.1097/mpg.0000000000000375.

2. Carter B, Fedorowicz Z. Antiemetic treatment for acute gastroenteritis in children: an updated Cochrane systematic review with meta-analysis and mixed treatment comparison in a Bayesian framework. BMJ Open. 2012;2(4):e000622-e000622. Available from: 10.1136/bmjopen-2011-000622.

3. Freedman SB, Soofi SB, Willan AR, et al. Oral Ondansetron Administration to Nondehydrated Children With Diarrhea and Associated Vomiting in Emergency Departments in Pakistan: A Randomized Controlled Trial. Ann Emerg Med. 2019;73(3):255-265. Available from: 10.1016/j. annemergmed.2018.09.011; https://dx.doi.org/10.1016/j.annemergmed.2018.09.011.

4. Freedman SB, Hall M, Shah SS, et al. Impact of Increasing Ondansetron Use on Clinical Outcomes in Children With Gastroenteritis. JAMA Pediatr. 2014;168(4):321-321. Available from: 10.1001/jamapediatrics.2013.4906;https://dx.doi.org/10.1001/jamapediatrics.2013.4906.

5. Cheng A. Emergency department use of oral ondansetron for acute gastroenteritis-related vomiting in infants and children. Paediatr Child Health. 2011;16(3):177-179. Available from: 10.1093/pch/16.3.177;https://dx.doi.org/10.1093/pch/16.3.177. 